\title{
Thyroid Functions in Long-Term Survivors of Pediatric Hodgkin's Lymphoma Treated with Chemotherapy and Radiotherapy
}

\author{
Metin Demirkaya1, Betül Sevinir1, Halil Sağlam2, Lütfi Özkan3, Okan Akacıl4 \\ ${ }^{1}$ Division of Pediatric Oncology, Department of Pediatrics, Uludag University, Medical Faculty, Bursa, Turkey \\ ${ }^{2}$ Division of Pediatric Endocrinology, Department of Pediatrics, Uludag University, Medical Faculty, Bursa, Turkey \\ ${ }^{3}$ Department of Radiation Oncology, Uludag University, Medical Faculty, Bursa, Turkey \\ ${ }^{4}$ Department of Pediatrics, Uludag University, Medical Faculty, Bursa, Turkey
}

\begin{abstract}
Objective: Post-treatment endocrine disturbances are common in cancer patients who have received radiotherapy or chemotherapy. The objective of this study was to evaluate the thyroid functions of long-term survivors of pediatric Hodgkin's lymphoma treated with chemotherapy and radiotherapy.

Methods: Thyroid functions of 55 Hodgkin's lymphoma patients (M/F:2.05/1) in complete remission were evaluated retrospectively.

Results: The mean age of the patients at diagnosis was $10.35 \pm 4.09$ (range: $2.83-17$ ) years and the mean follow-up period was $5.54 \pm 3.68$ (range: 0.92-13.92) years. All patients received chemotherapy; a total of 50 patients $(90.9 \%)$ underwent radiotherapy, $42(76.4 \%)$ of whom received neck/mantle radiotherapy. Thyroid function tests were abnormal in $14(24.5 \%)$ patients and normal - in the remaining $41(74.5 \%)$. A diagnosis of subclinical and overt hypothyroidism was made in 11 (78.6\%) and $3(21.4 \%)$ patients with abnormal thyroid function tests, respectively. Nearly one-fourth $(21.4 \%)$ of all thyroid function disorders were detected in the first year of follow-up. A statistically significant correlation was found between the dose of mantle radiotherapy and thyroid function disorder $(p=0.002)$. In addition, statistically significant correlations were established between thyroid examination or thyroid ultrasonography findings and thyroid functions ( $<0.001$ or $p=0.006$, respectively).

Conclusions: Radiation-induced thyroid disorders may develop in pediatric Hodgkin's lymphoma patients in complete remission starting as early as the first year after treatment and are dose-dependent. Patients, particularly those who have been exposed to radiotherapy of the neck, must be followed up closely for occurrence of thyroid dysfunctions.

Key words: Hodgkin disease, children, late effect
\end{abstract}

Conflict of interest: None declared

Received: 14.03.2001

Accepted: 23.04 .2011

\section{Introduction}

In parallel with enhanced survival rates of pediatric Hodgkin's lymphoma patients by current chemotherapy and radiotherapy protocols, an increase in early and late complication rates have also been noted. Common late complications of childhood cancers after treatment include neurological, cardiac, pulmonary and gonadal disorders, reduction in bone mass, defective bone and soft tissue development, and increased susceptibility to secondary malignant tumors $(1,2,3,4,5,6,7,8,9)$.

Hyperthyroidism including Graves' disease, thyroiditis, hypothyroidism, thyroid nodules and thyroid cancers are the most commonly encountered thyroid gland disorders that are known to be related with radiotherapy $(6,10,11,12,13)$.

The objective of this study was to evaluate thyroid function in pediatric Hodgkin's lymphoma patients in complete remission with chemotherapy and radiotherapy.

\section{Methods}

In this retrospective study, we assessed the thyroid functions in 55 pediatric Hodgkin's lymphoma patients in complete remission who were treated in the Department of Pediatric Oncology at Uludag University Medical Faculty between January 1995 and December 2008.

\section{Address for Correspondence}

Metin Demirkaya MD, Division of Pediatric Oncology, Department of Pediatrics, Uludag University, Medical Faculty, 16059 Görükle, Bursa, Turkey Tel: +90 2242950432 Fax: +90 2244428143 E-mail: demirkayametin@hotmail.com

(๑) Journal of Clinical Research in Pediatric Endocrinology, Published by Galenos Publishing. 
Recurrence occurred only in 2 patients who received a second treatment regimen and were then followed up in complete remission. Physical and thyroid examination findings, thyroid stimulating hormone (TSH), free triiodothyronine $\left(\mathrm{fT}_{3}\right)$, free thyroxine $\left(\mathrm{fT}_{4}\right)$, total $\mathrm{T}_{3}$, and total $\mathrm{T}_{4}$ levels, thyroid imaging (ultrasonography and/or scintigraphy), thyroid antibody data, serum thyroglobulin and calcitonin levels were obtained from patient records and evaluated.

Age and gender of the patients, stage and histopathological subgroup of the disease, chemotherapy protocols, number of cycles, radiotherapy region and dose, and follow-up durations were noted. Patients with hypothyroidism were divided into two groups as subclinical hypothyroidism and overt hypothyroidism.

The study was approved by the local ethics committee.

The following four chemotherapy protocols were used: i) ABVD (adriamycin $25 \mathrm{mg} / \mathrm{m}^{2} 1$ st and $15^{\text {th }}$ days, intravenously (i.v.), bleomycin $10 \mathrm{mg} / \mathrm{m}^{2} 1^{\text {st }}$ and $15^{\text {th }}$ days i.v., vinblastine 6 $\mathrm{mg} / \mathrm{m}^{2} 1^{\text {st }}$ and $15^{\text {th }}$ days i.v., dacarbazine $375 \mathrm{mg} / \mathrm{m}^{2} 1^{\text {st }}$ and $15^{\text {th }}$ days i.v.); ii) COPP (cyclophosphamide $600 \mathrm{mg} / \mathrm{m}^{2} 1$ st and $8^{\text {th }}$ days i.v., vincristine $1.4 \mathrm{mg} / \mathrm{m}^{2}$ 1st and $8^{\text {th }}$ days i.v., procarbazine $100 \mathrm{mg} / \mathrm{m}^{2}$ 1-14 days p.o., prednisolone 40 $\mathrm{mg} / \mathrm{m}^{2}$ 1-14 days p.o.), iii) MOPP (mechlorethamine $5 \mathrm{mg} / \mathrm{m}^{2}$ $1^{\text {st }}$ and $8^{\text {th }}$ days i.v., vincristine $1.4 \mathrm{mg} / \mathrm{m}^{2} 1^{\text {st }}$ and $8^{\text {th }}$ days i.v., procarbazine $100 \mathrm{mg} / \mathrm{m}^{2}$ 1-14 days p.o., prednisolone 40 $\mathrm{mg} / \mathrm{m}^{2}$ 1-14 days p.o.), iv) MOPP/ABVD or COPP/ABVD hybrid treatment protocol.

The COPP, MOPP or hybrid protocols were applied to the patients between 1995 and 1997, while ABVD treatment protocol was given after 1997. All subjects, except for those who experienced recurrence, received 3-6 chemotherapy cycles.

Radiotherapy regions were grouped as: i) neck region and mantle radiotherapy ii) mediastinum, iii) other regions. The patients received a total dose of 2520 centigrays (cGy) mantle radiotherapy with a daily dose of $180 \mathrm{cGy}$. The dose of radiotherapy was completed to 3060 or 3600 in patients with remaining lymphadenopathy after standard dose chemotherapy and in those with residual disease after radiotherapy, respectively.

Serum total $T_{3}$, total $T_{4}, \mathrm{fT}_{3}, \mathrm{fT}_{4}$ and TSH levels were analyzed by Immulite 2000 autoanalyzer using chemiluminescent microparticle immunoassay (CMIA) method (Abbott Laboratories).

The statistical analyses were performed using SPSS (Statistical Package for the Social Sciences) for Windows 13.0 software. Comparisons of continuous variables in multiple groups were made applying the Kruskal-Wallis test, while comparisons between two groups were made using the Mann-Whitney $U$ test. Inter-group differences of categorical variables were determined by the Pearson's chi-square test and Fisher's exact test. Results were presented as mean \pm standard deviation (SD) values. A p-value of less than 0.05 was considered statistically significant.

\section{Results}

Table 1 lists the demographic features of the 55 patients included in this study. The patients were classified according to their thyroid function tests as normal (group 1) and abnormal (group 2). The total study population consisted of 37 males (67.3\%) and 18 females (32.3\%); male/female ratio was 2.05/1. Thyroid function tests were normal in 41 (74.5\%) patients, while thyroid dysfunction was present in 14 (25.5\%) patients. No statistically significant difference was found with regard to thyroid dysfunction between genders.

The mean ages of the patients at diagnosis and when the study was performed were $10.35 \pm 4.09$ (range: $2.83-17$ ) years and 15.84 \pm 3.91 (range: 6.91-24) years, respectively. The mean follow-up duration was $5.54 \pm 3.68$ (range 0.92-13.92) years. No statistically significant difference was found with regard to gender distribution or follow-up duration between groups 1 and 2 .

Thyroid examination was normal (grade 0) in 40 (72.7\%) patients, while grade I, grade $\|$, and grade III goiter was detected in 9 (16.4\%), 5 (9.1\%), and 1 (1.8\%) patient, respectively. Thyroid ultrasonography performed in 45 (81.8\%) out of 55 patients was normal in 41 (91.1\%) and abnormal in $4(8.9 \%)$ patients (nodules in 3 patients and hypoechoic cyst in 1 patient).

Thyroid functions were normal in $95 \%$ of patients with normal thyroid examination findings, in $22.2 \%$ of patients with grade I goiter and in $20 \%$ of patients with grade II goiter. One patient with grade III goiter had abnormal thyroid functions. Thyroid functions were significantly correlated with thyroid examination findings $(p<0.001)$.

Thyroid ultrasonography was performed in $87.8 \%$ and $64.3 \%$ of subjects in group 1 and 2, respectively. Thyroid

\begin{tabular}{lcc}
\hline \multicolumn{3}{l}{ Table 1. Demographic features of the patients } \\
\hline & \multicolumn{2}{c}{ Thyroid functions } \\
Normal & Abnormal \\
\hline Number of patients $[n,(\%)]$ & $41(74.5)$ & $14(25.5)$ \\
Gender [n, $(\%)]$ & & $11(29.7)$ \\
Male & $26(70.3)$ & $3(16.7)$ \\
Female & $15(83.3)$ & $10.07 \pm 3.89$ \\
Age at diagnosis & $10.45 \pm 4.2$ & $(2.83-16.41)$ \\
$\quad$ (years), (mean $\pm S D)]$ & $(3.66-17)$ & $15.07 \pm 3.27$ \\
Age at time of study & $16.1 \pm 4.11$ & $(10.08-20.91)$ \\
[(years), (mean $\pm S D)]$ & $(6.91-24)$ & $5.01 \pm 2.83$ \\
Mean follow-up duration & $5.78 \pm 4.08$ & $(0.92-11.33)$ \\
[(years), (mean $\pm S D)]$ & $(0.92-16.25)$ & \\
\hline SD: standard deviation & &
\end{tabular}


functions were normal in $85.7 \%$ of patients with normal ultrasonographic findings; in contrast, thyroid dysfunction was found in all 4 patients with abnormal ultrasonographic findings. A significant correlation was observed between thyroid ultrasonography findings and thyroid functions $(p=0.006)$. The 4 patients in group 2 who showed abnormal ultrasonographic findings included 3 patients with nodules and one patient with a $12 \times 17 \mathrm{~mm}$ hypoechoic cystic degeneration on the right thyroid lobe. Hypothyroidism was present in all 4 patients. Thyroglobulin levels in the case with hypoechoic cyst were higher than normal and the patient underwent thyroid surgery. The cyst was benign in nature on histopathological evaluation.

As shown in Table 2, histopathological typing revealed that the Hodgkin's lymphoma was nodular sclerosing in 28 (50.9\%) patients, mixed-cell in 23 (41.8\%) and lymphocyte-rich in 4 (7.3\%) patients. According to the Hodgkin's lymphoma staging,

\begin{tabular}{|c|c|c|}
\hline & \multicolumn{2}{|c|}{ Thyroid functions } \\
\hline & Normal $(n=41)$ & Abnormal $(n=14)$ \\
\hline \multicolumn{3}{|l|}{ Histopathology [n, (\%)] } \\
\hline nodular sclerosing & $20(71.4)$ & $8(28.6)$ \\
\hline mixed-cell & $17(73.9)$ & $6(26.1)$ \\
\hline lymphocyte-rich & $4(100)$ & - \\
\hline \multicolumn{3}{|l|}{ Stage $[\mathrm{n},(\%)]$} \\
\hline I & $11(84.6)$ & $2(15.4)$ \\
\hline II & $12(66.7)$ & $6(33.3)$ \\
\hline III & $13(68.4)$ & $6(31.6)$ \\
\hline IV & $5(100)$ & - \\
\hline \multicolumn{3}{|l|}{ Chemotherapy [n, (\%)] } \\
\hline ABVD & $35(71.4)$ & $14(28.6)$ \\
\hline COPP & $2(100)$ & - \\
\hline MOPP/ABVD & $4(100)$ & - \\
\hline \multicolumn{3}{|l|}{ Number of cycles [n, $(\%)]$} \\
\hline 3 cycles & $20(71.4)$ & $8(28.6)$ \\
\hline 6 cycles & $21(77.8)$ & $6(22.2)$ \\
\hline Radiotherapy [n, (\%)] & $36(72)$ & $14(28)$ \\
\hline Neck/mantle region [n, $(\%)]$ & $30(71.4)$ & $12(28.6)$ \\
\hline \multicolumn{3}{|l|}{ Neck/mantle dose ${ }^{*}[n,(\%)]$} \\
\hline 2520 cGy & $16(72.7)$ & $6(27.3)$ \\
\hline 3060 cGy & $13(92.9)$ & $1(7.1)$ \\
\hline $3600 \mathrm{cGy}$ & $1(16.7)$ & $5(83.3)$ \\
\hline
\end{tabular}

$13(23.6 \%), 18$ (32.7\%), 19 (34.5\%) and 5 (9.1\%) patients were classified as having stages I, II, III, and IV, respectively.

$A B V D, C O P P$, and MOPP/ABVD hybrid protocols were applied to 49 (89.1\%), 2 (3.6\%), and 4 (7.3\%) patients, respectively. Three and 6 cycles of chemotherapy were given to $50.9 \%$ and $49.1 \%$ of all patients, respectively.

Out of the 55 patients in our study, 50 (90.9\%) received radiotherapy, $42(76.4 \%)$ of whom underwent neck/mantle radiotherapy. Twenty-two (52.4\%), 14 (33.3\%), and 6 (14.3\%) patients received a total dose of 2520 cGy, 3060 cGy, and 3600 cGy neck/mantle radiotherapy, respectively. Twenty-two $(52.4 \%)$ out of 42 patients who received neck/mantle radiotherapy also received radiotherapy to other regions, while the remaining 20 (47.6\%) patients did not.

Statistical analysis revealed no differences with regard to thyroid function among the different histopathological groups, nor among the various stage or chemotherapy groups. There were also no differences detected among patients who were exposed to 3 or to 6 cycles of treatment. Exposure or non-exposure to radiotherapy or to radiotherapy to the neck/mantle region also did not appear to lead to differences in thyroid function. On the other hand, statistically significant differences were found regarding thyroid dysfunction among patients receiving different doses of neck/mantle radiotherapy. Thyroid function was normal in $72.7 \%, 92.9 \%$, and $16.7 \%$ of patients who received a total dose of 2520 cGy, 3060 cGy, and 3600 cGy neck/mantle radiotherapy, respectively. However, binary comparisons of the three doses revealed statistically significant differences between the 2520 cGy dose and the $3600 \mathrm{cGy}$ dose $(p=0.022)$ and also between the $3060 \mathrm{cGy}$ dose and 3600 cGy dose $(p=0.002)$.

Subclinical and overt hypothyroidism was diagnosed in $11(78.6 \%)$ and $3(21.4 \%)$ patients with abnormal thyroid function tests, respectively. Table 3 lists the features in individual patients with abnormal thyroid function tests. Thyroid dysfunction was detected after the first, second, third, fourth and fifth year of treatment in 3, 2, 3, 4 and 2 patients, respectively. No statistically significant correlation was found between time passed after treatment and thyroid dysfunction.

\section{Discussion}

In parallel to enhanced survival rates of pediatric Hodgkin's lymphoma patients by current chemotherapy and radiotherapy protocols, an increase in early and late complication rates was also noted $(14,15,16)$. The risk of thyroid disorder development was found to be $52 \%$ and $67 \%$ after 20 and 26 years of survival, respectively, in a study including 1787 patients with Hodgkin's lymphoma (14). We found a thyroid disorder rate of $25.5 \%$ within a mean follow-up duration of 5.54 years in our study group of 55 patients, all in complete remission following chemotherapy and radiotherapy. Of the 14 patients who showed abnormal thyroid function, $78.6 \%$ were diagnosed as subclinical and $11.4 \%$ as overt hypothyroidism. 
Subclinical hypothyroidism following exposure to radiotherapy has been reported to have a high incidence in Hodgkin's patients (17). Hunger et al (18) detected subclinical chemical hypothyroidism in $9(16 \%)$ out of 57 patients who received a combination of chemotherapy and low-dose radiotherapy in their study with a mean follow-up duration of 6.7 years. In another study (19), subclinical hypothyroidism was found in 22 (63\%) out of 35 patients with Hodgkin's lymphoma who received mantle radiotherapy; some of these patients reportedly recovered within time. Periodical thyroid function tests revealed altered levels of at least one thyroid hormone. Elevation in TSH level was the most commonly encountered disorder. In one study (20), a high TSH was reported in 29 $(50 \%)$ out of 58 patients who had received chemotherapy and low-dose (15-25 Gy) mantle radiotherapy. In our study, we also observed a significant correlation between thyroid dysfunction and dose of the neck/mantle radiotherapy.

Radiotherapy dose, which was 44-45 Gy previously, was reduced to 15-25.5 Gy due to late complications (1). In a study (21) on 119 Hodgkin's lymphoma patients, TSH levels were found to be elevated in $17 \%$ and $78 \%$ of those who received low-dose (lower than 2600 rad) and high-dose (higher than 2600 rad) mantle radiotherapy to the neck, respectively. Since thyroid dysfunction occurred 18 and 31 months after low- and high-dose radiotherapy, respectively, it is generally stated that it takes a time period of 3 to 5 years for thyroid function to be affected. In another study (6) with a mean follow-up duration of 30 years, thyroid dysfunction, the most common $(17.1 \%)$ of which was hypothyroidism ( $p=0.0001)$, was detected in 34\% of 1791 Hodgkin's lymphoma patients who received chemotherapy and radiotherapy; the risk of hypothyroidism was increased by high-dose radiotherapy, advanced diagnosis age and female gender. Hyperthyroidism was detected in $5 \%$ of these patients - an 8-fold increased risk compared with controls $(p=0.0001)$. The risk of thyroid nodule development was 27-fold that of controls after a mean latent period of 14 years in this same study and the risk of nodule development was correlated with high dose radiotherapy (higher than $2500 \mathrm{cGy}$ ) and female gender. 7\% of the nodules were of malignant nature. In addition, thyroid cancer was found in 20 survivors in that study, which is 18-fold of that expected in a community.

\begin{tabular}{|c|c|c|c|c|c|c|c|c|}
\hline & $\begin{array}{l}\text { Age at } \\
\text { diagnosis } \\
\text { (years) }\end{array}$ & Gender & Stage & $\begin{array}{l}\text { Chemotherapy } \\
\text { protocol/number } \\
\text { of cycles }\end{array}$ & $\begin{array}{c}\text { Neck/mantle } \\
\text { RT } \\
\text { dose (cGy) }\end{array}$ & $\begin{array}{c}\text { Thyroid } \\
\text { examination } \\
\text { grade }\end{array}$ & $\begin{array}{l}\text { Thyroid } \\
\text { USG }\end{array}$ & $\begin{array}{l}\text { Thyroid } \\
\text { dysfunction } \\
\text { time }\end{array}$ \\
\hline \multicolumn{9}{|c|}{$\begin{array}{l}\text { Overt } \\
\text { hypothyroidism }\end{array}$} \\
\hline Patient 1 & 16.4 & $\mathrm{~F}$ & 1 & ABVD/3 & 2520 & 1 & - & $1^{\text {st }}$ year \\
\hline Patient 2 & 9.8 & $M$ & $2 b$ & ABVD/3 & 3060 & 1 & normal & $5^{\text {th }}$ year \\
\hline Patient 3 & 10.8 & $M$ & 1 & ABVD/3 & 2520 & 1 & nodule & $3^{\text {rd }}$ year \\
\hline \multicolumn{9}{|c|}{$\begin{array}{l}\text { Subclinical } \\
\text { hypothyroidism }\end{array}$} \\
\hline Patient 4 & 13.8 & M & $3 s b$ & ABVD/6 & 2520 & 1 & normal & $2^{\text {nd }}$ year \\
\hline Patient 5 & 14.6 & $M$ & 3 & ABVD/6 & 3600 & 1 & - & $4^{\text {th }}$ year \\
\hline Patient 6 & 11.6 & $M$ & $2 b$ & ABVD/3 & 3600 & 2 & nodule & $4^{\text {th }}$ year \\
\hline Patient 7 & 8.9 & $M$ & 2 & ABVD/3 & 3600 & 2 & normal & $3^{\text {rd }}$ year \\
\hline Patient 8 & 9.2 & $\mathrm{~F}$ & 2 & ABVD/3 & 2520 & 2 & normal & $1^{\text {st }}$ year \\
\hline Patient 9 & 2.8 & $M$ & $3 s$ & ABVD/6 & - & 1 & - & $>5^{\text {th }}$ year \\
\hline Patient 10 & 14.8 & $M$ & $3 s b$ & ABVD/6 & - & 0 & - & $3^{\text {rd }}$ year \\
\hline Patient 11 & 6.5 & $M$ & 2 & ABVD/3 & 2520 & 1 & nodule & $4^{\text {th }}$ year \\
\hline Patient 12 & 6.7 & $M$ & $3 s$ & ABVD/6 & 3600 & 0 & - & $1^{\text {st }}$ year \\
\hline Patient 13 & 9.2 & M & $3 s$ & ABVD/6 & 3600 & 2 & normal & $2^{\text {nd }}$ year \\
\hline Patient 14 & 5.8 & $\mathrm{~F}$ & 2 & ABVD/3 & 2520 & 3 & cyst & $>5^{\text {th }}$ year \\
\hline
\end{tabular}


In a study (14) on 1677 patients with Hodgkin's lymphoma who received radiotherapy to the thyroid gland region, at least one nodule was detected in $2.6 \%$ of them. The risk of thyroid nodule development was found to be increased 27 -fold in a controlled study after a mean latent period of 14 years. $7 \%$ of the nodules were of malignant nature. Independent risk factors were reported as female gender and high dose (higher than 25 Gy) of radiotherapy (6). The risk of benign or malignant thyroid disease development subsequent to chemotherapy and radiotherapy is reported to be increased 1.74- or 36.4-fold, respectively. The length of duration after treatment and the age at which the treatment was initiated increase this risk. Although radiotherapy is significantly correlated with such risks, the risk caused by chemotherapy is not clear. However, it is generally accepted that a combination of chemotherapy and radiotherapy further enhances the risk of benign or malignant thyroid disease (22).

A study (23) on 1380 patients with Hodgkin's lymphoma reported thyroid neoplasm in $19(1.4 \%)$ patients within a mean follow-up period of 15.3 years (range: 4.2-29.7 years). Radiotherapy, chemotherapy and a combination of radiotherapy plus chemotherapy were applied to $5(26 \%), 1(5 \%)$ and 13 (69\%) patients, respectively. Cumulative incidence for secondary malignancy was calculated as $10.6 \%$ and $26.3 \%$ on the $20^{\text {th }}$ and $30^{\text {th }}$ years, respectively. In another study (24) conducted between 1960 and 1990, thyroid malignancies were detected in $14(1.5 \%)$ out of 930 patients with Hodgkin's lymphoma within a mean follow-up period of 14.4 (range: 8.5-23) years. Another study (25) reported that the overall cumulative 10- and 20-year second malignancy rates were $2.45 \%$ and $7.29 \%$, respectively, in 358 pediatric Hodgkin's lymphoma patients, and that only one patient who received chemotherapy alone developed thyroid malignancy on the $13^{\text {th }}$ year after treatment. Acharya et al (12) reported that 18 out of 33 patients with pediatric Hodgkin's lymphoma developed thyroid neoplasm after a mean mantle radiotherapy dose of 2400 cGy (range: 1000-4200 cGy) to the neck within a mean period of 13 (range 6.2-30.1) years and that 39\% of those neoplasms were of malignant nature (13 papillary carcinoma and 2 follicular carcinoma). Another study (26) found that $10 \%$ of 67 patients developed thyroid nodules of malignant nature 16.2 years after completion of radiotherapy with an average 35 Gy dose.

In our study, we detected thyroid nodules in 4 (7.3\%) patients within an average follow-up period of $5.5 \pm 3.7$ years. One of these patients received surgery and the nodule was reported to be benign in nature. One reason why we did not encounter malignant thyroid nodules in our patients might be the relatively short duration of follow-up after completion of treatment.

In conclusion, our study shows that thyroid dysfunction occurs in approximately one-fourth of pediatric Hodgkin's lymphoma patients within an average period of 5.5 years after completion of treatment. Our findings also demonstrate that thyroid functions can be affected as early as the first year after completion of treatment. Thyroid dysfunction was found to statistically correlate with the dose of neck/mantle radiotherapy. The reason why the rate of thyroid dysfunction in our study was smaller than those in other reports could be that we applied a lower dose as mantle radiotherapy. It is also known that the rate of detection of thyroid nodules increases with duration of follow-up. Thus, periodic evaluation of the thyroid gland in Hodgkin's lymphoma patients who received radiotherapy and chemotherapy needs to be started at an early period after treatment and continued for many years.

\section{Conflict of Interest}

No author of this paper has a conflict of interest, including specific financial interests, relationships, and/or affiliations relevant to the subject matter or materials included in this manuscript.

\section{References}

1. Hudson MM, Onciv M, Donaldson SS. Hodgkin lymphoma. In: Pizzo PA, Poplack DG (eds). Principles and practice of pediatric oncology. $5^{\text {th }}$ ed. Philadelphia: Lippincott Williams and Wilkins; 2006. p.695-721.

2. Lanzkowsky P. Manuel of pediatric hematology and oncology. 4th ed. Burlington: Elsevier Academic Press; 2005;453-490.

3. Büyükpamukçu $M$, Atahan L, Cağlar $M$, Kutluk $T$, Akyüz $C$, Hazar V. Hodgkin's disease in Turkish children: clinical characteristics and treatment results of 210 patients. Pediatr Hematol Oncol 1999:16:119-129.

4. Oguz A, Karadeniz C, Okur FV, Citak EC, Pinarli FG, Bora H, Akyurek N. Prognostic factors and treatment outcome in childhood Hodgkin disease. Pediatr Blood Cancer 2005;45: 670-675.

5. Ertem U, Duru F, Dağdemir A, Taçyildiz N, Pamir A, Akçayöz A, Uluoğlu O, Teziç T. Hodgkin's disease in 82 Turkish children diagnosed over a 10 year period: epidemiological, clinical, and histopathologic features and prognosis with prolonged chemotherapy. Pediatr Hematol Oncol 1997;14:359-366.

6. Sklar C, Whitton J, Mertens A, Stovall M, Green D, Marina N, Greffe B, Wolden S, Robison L. Abnormalities of the thyroid in survivors of Hodgkin's disease: data from the Childhood Cancer Survivor Study. J Clin Endocrinol Metab 2000;85: 3227-3232.

7. Gold DG, Neglia JP, Dusenbery KE. Second neoplasms after megavoltage radiation for pediatric tumors. Cancer 2003:97:2588-2596.

8. Barrera M, Shaw AK, Speechley KN, Maunsell E, Pogany L. Educational and social late effects of childhood cancer and related clinical, personal, and familial characteristics. Cancer 2005;104:1751-1760.

9. Meadows AT, Friedman DL, Neglia JP, Mertens AC, Donaldson SS, Stovall M, Hammond S, Yasui Y, Inskip PD. Second neoplasms in survivors of childhood cancer: findings from the Childhood Cancer Survivor Study cohort. J Clin Oncol 2009;27:2356-2362

10. Bhatia S, Blatt J, Meadows AT. Late effects of childhood cancer and its treatment. In: Pizzo PA, Poplack DG (eds). Principles and practice of pediatric oncology. $5^{\text {th }}$ ed. Philadelphia: Lippincott Williams and Wilkins; 2006. p.1490-1514.

11. Schellong G, Pötter R, Brämswig J, Wagner W, Prott FJ, Dörffel W, Körholz D, Mann G, Rath B, Reiter A, Weissbach G, Riepenhausen M, Thiemann M, Schwarze EW. High cure rates and reduced long-term toxicity in pediatric Hodgkin's disease: the German-Austrian multicenter trial DAL-HD-90. The German-Austrian Pediatric Hodgkin's Disease Study Group. J Clin Oncol 1999;17:3736-3744. 
12. Acharya S, Sarafoglou K, LaQuaglia M, Lindsley S, Gerald W, Wollner N, Tan C, Sklar C. Thyroid neoplasms after therapeutic radiation for malignancies during childhood or adolescence. Cancer 2003;97:2397-2403.

13. Gözdasoglu S, Cavdar AO, Babacan E, Mengübas K, Yavuz G, Unal E, Pamir A, Ocal G, Haluk Gökçora I. Late effects of chemoradiotherapy in pediatric Hodgkin's disease. J Chemother 1995;7:463-466.

14. Hancock SL, Cox RS, McDougall IR. Thyroid diseases after treatment of Hodgkin's disease. $N$ Engl J Med 1991;325:599-605.

15. von der Weid NX. Adult life after surviving lymphoma in childhood. Support Care Cancer 2008;16:339-345.

16. Aleman BM, van den Belt-Dusebout AW, Klokman WJ, Van't Veer MB, Bartelink $H$, van Leeuwen FE. Long-term cause-specific mortality of patients treated for Hodgkin's disease. J Clin Oncol 2003;21:3431-3439.

17. Shafford EA, Kingston JE, Healy JC, Webb JA, Plowman PN, Reznek $\mathrm{RH}$. Thyroid nodular disease after radiotherapy to the neck for childhood Hodgkin's disease. $\mathrm{Br} J$ Cancer 1999;80:808-814.

18. Hunger SP, Link MP, Donaldson SS. ABVD/MOPP and low-dose involved-field radiotherapy in pediatric Hodgkin's disease: the Stanford experience. J Clin Oncol 1994;12:21602166.

19. Nair N, Advani SH. Follow up of alterations in thyroid hormones and thyrotropin in patients of Hodgkin's diseasegiven mantle radiation. J Assoc Physicians India 1990;38:623-624.

20. Moryl-Bujakowska A, Balwierz W, Sztefko K. [Preliminary results of thyroid function assessment in children and adolescents with Hodgkin's disease (HD) treated according to PGP-HD-97 protocoll. Przegl Lek 2004:61:81-84.
21. Constine LS, Donaldson SS, McDougall IR, Cox RS, Link MP, Kaplan HS. Thyroid dysfunction after radiotherapy in children with Hodgkin's disease. Cancer 1984;53:878-883.

22. Lin HM, Teitell MA. Second malignancy after treatment of pediatric Hodgkin disease. J Pediatr Hematol Oncol 2005:27:28-36.

23. Bhatia $S$, Yasui $Y$, Robison LL, Birch JM, Bogue MK, Diller $L$, DeLaat C, Fossati-Bellani F, Morgan E, Oberlin O, Reaman G, Ruymann FB, Tersak J, Meadows AT; Late Effects Study Group. High risk of subsequent neoplasms continues with extended follow-up of childhood Hodgkin's disease: report from the Late Effects Study Group. J Clin Oncol 2003;21: 4386-4394.

24. Constine LS, Tarbell N, Hudson MM, Schwartz C, Fisher SG, Muhs AG, Basu SK, Kun LE, Ng A, Mauch P, Sandhu A, Culakova E, Lyman G, Mendenhall N. Subsequent malignancies in children treated for Hodgkin's disease: associations with gender and radiation dose. Int J Radiat Oncol Biol Phys 2008;72:24-33.

25. Capra M, Hewitt M, Radford M, Hayward J, Weston CL, Machin D; Children's Cancer and Leukaemia Group. Long-term outcome in children with Hodgkin's lymphoma: the United Kingdom Children's Cancer Study Group HD82 trial. Eur J Cancer 2007:43:1171-1179.

26. Metzger ML, Howard SC, Hudson MM, Gow KW, Li CS, Krasin MJ, Merchant T, Kun L, Shelso J, Pui CH, Shochat SJ, McCarville MB. Natural history of thyroid nodules in survivors of pediatric Hodgkin lymphoma. Pediatr Blood Cancer 2006;46:314-319. 